\title{
Traumatic brain injury and olfaction: a systematic review
}

\author{
Peter William Schofield ${ }^{1,2}$ *, Tammie Maree Moore ${ }^{1}$ and Andrew Gardner ${ }^{1,2}$ \\ ${ }^{1}$ Neuropsychiatry Service, Hunter New England Mental Health, Newcastle, NSW, Australia \\ ${ }^{2}$ Centre for Translational Neuroscience and Mental Health, University of Newcastle, Newcastle, NSW, Australia
}

Edited by:

Yun Chen, US Army Medical Research

Institute of Chemical Defense, USA

\section{Reviewed by:}

Charles WWilkinson, University of Washington, USA

David Keyser, Uniformed Services

University of the Health Sciences,

USA

Paul Rapp, Uniformed Services

University of the Health Sciences, USA

\section{*Correspondence:}

Peter William Schofield,

Neuropsychiatry Service, Hunter New

England Mental Health, PO BOX 833,

Newcastle, NSW 2300, Australia

e-mail: peter.schofield@hnehealth.

nsw.gov.au
Traumatic brain injury (TBI) is a common condition that is often complicated by neuropsychiatric sequelae that can have major impacts on function and quality of life. An alteration in the sense of smell is recognized as a relatively common complication of TBl; however in clinical practice, this complication may not be sought or adequately characterized. We conducted a systematic review of studies concerned with olfactory functioning following TBI. Our predetermined criteria led to the identification of 25 studies published in English, which we examined in detail. We have tabulated the data from these studies in eight separate tables, beginning with Table 1, which highlights each study's key findings, and we provide a summary/synthesis of the findings in the accompanying results and discussion sections. Despite widely differing methodologies, the studies attest to a high frequency of post-TBI olfactory dysfunction and indicate that its presence can serve as a potential marker of additional structural or functional morbidities.

Keywords: brain injury, olfaction, anosmia, trauma, review

\section{INTRODUCTION}

Traumatic brain injury (TBI) is a common, potentially preventable cause of mortality, and major morbidity. Neuropsychiatric sequelae, including cognitive, behavioral, and psychiatric symptoms and signs, may be present to varying degrees following a TBI according to the premorbid characteristics of the patient, its nature and severity, and the time elapsed since the injury. When specifically sought, olfactory functioning disturbances are common following TBI and, if present, can have a significant impact on quality of life (1). Reduced appreciation of food, drink, and other smell-laden sensual experiences; loss of employment, when this depends on an intact sense of smell; and increased danger from environmental hazards (e.g., volatile agents/gas, fires, spoiled food) are among the most obvious potential consequences of post-TBI olfactory deficits.

The availability in recent years of standardized instruments for assessing olfaction has enabled researchers to investigate with greater precision and rigor the associations between TBI (and related phenomena) and altered olfactory functioning $(2,3)$. However, despite the functional relevance of olfactory impairments following TBI, systematic objective quantitative testing of olfaction is not, at least in our own clinical experience, routinely undertaken. In light of this and because the substantial and growing literature suggests that olfactory impairment is relatively common and clinically important, we thought that a systematic review would be timely.

In the course of this review, issues of high clinical relevance are raised that, as far as we are aware, have not recently been systematically examined within the same work including: what relationship exists between TBI severity and the risk for post-TBI olfactory impairment? How commonly does olfactory impairment arise following a TBI? What are the structural and functional correlates of post-TBI olfactory impairment? What is the prognosis for post-TBI olfactory impairment? What is the impact of post-TBI olfactory impairment on quality of life?

\section{MATERIALS AND METHODS}

The review was conducted in two stages. In stage 1 , articles were retrieved via online database searching. The online databases of PsycINFO, MEDLINE, EMBASE, Scopus, and COCHRANE were searched. Keywords and combinations of these words were used to search the databases comprehensively: diffuse axonal injury, brain hemorrhage, intracranial hemorrhage, brain edema, penetrating head injuries, olfaction disorders, olfactory perception, olfactory bulb, olfactory pathways, olfactory mucosa, olfactory receptor neurons, TBI, olfaction, olfactory, head injury, sense of smell, brain injury, smell, odor/odor, hyposmia, anosmia, brain damage, brain concussion, cerebral concussion, concussion, and craniocerebral trauma. Articles were limited to those that were published in Englishlanguage journals from 1980 to August 2013 and to studies in humans.

During stage 2, the titles and abstracts of articles were reviewed to assess eligibility for inclusion in this review. Articles were regarded as relevant and warranting inclusion in the review if they were human studies, using validated olfactory testing methods in distinct TBI populations. Where there was uncertainty about whether a study should be included based on the review of the title and abstract, the full article was retrieved (see Figure $\mathbf{1}$ for article exclusion results).

\section{DATA EXTRACTION}

Initially, one reviewer extracted data from the identified studies, including (1) participant demographics (TBI and control 


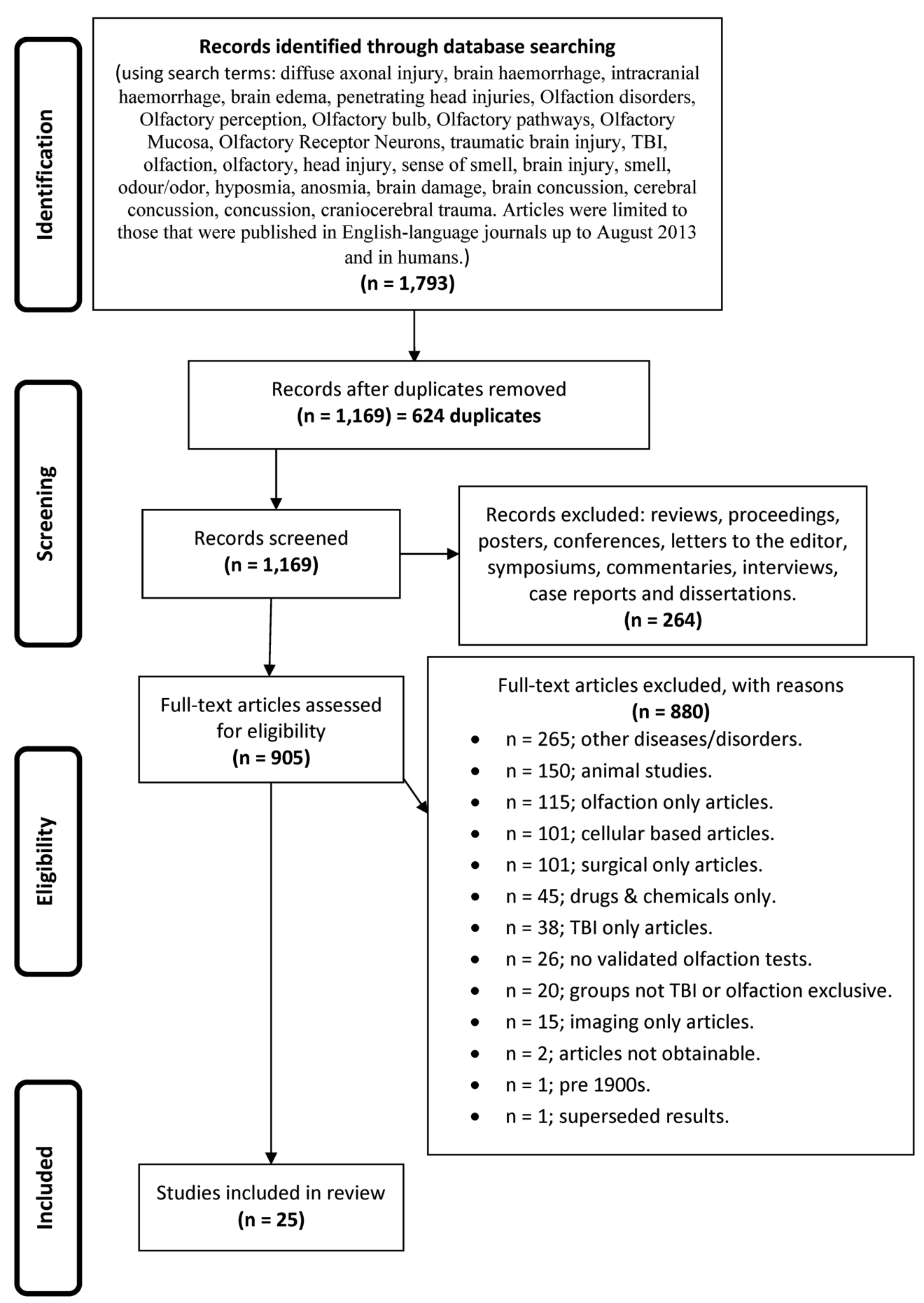

FIGURE 1 |The flow diagram depicting the search strategy, process, and exclusionary criteria by which the studies were selected for inclusion in this systematic review.

subjects), (2) characteristics of participants (TBI severity, duration of loss of consciousness (LOC), mechanism of injury), (3) olfactory testing paradigms (technique and data extraction), (4) time, elapsed since injury, (5) results of the study, and (6) study findings.

\section{RESULTS}

Our initial searches, based on the search strategies described in Figure 1, generated 1,793 hits. After duplicates were removed, we were left with 1,169 records, which were screened leading to removal of a further 264 records, leaving 905 full text articles that 
were further assessed for eligibility. As indicated in Figure 1, a further 880 were culled for the reasons listed.

\section{SCOPE, DEFINITIONS, AND METHODOLOGY OF THE STUDIES}

Table 1 provides a brief overview of the main goals and findings of each of the 25 studies that we examined in detail (4-28) and the subsequent Tables 2-8 provide further detail regarding aspects of the methodology, sample characteristics, etc. The studies ranged broadly in terms of their principal focus (Table 1). Most of the studies included individuals who had sustained a TBI, regardless of the presence or otherwise of olfactory problems $(5,6,9-12,14-$ $17,19,21-24,26,27)$ while in eight studies participants with TBI were selected for the presence of olfactory complaints or established olfactory impairment $(4,7,8,13,18,20,25,28)$. While most of the studies were cross sectional in design, several had an important longitudinal aspect $(7,9,18,26)$. The individual study sample sizes ranged from 5 individuals in the single qualitative study (25) to 367 (15). Only one of the studies was concerned with children with TBI specifically (14) (Table 2).

Traumatic brain injury severity was variously defined by the Glasgow Coma Score (GCS) $(5,6,9,15,16,19,24,25,27)$, the duration of post-traumatic amnesia (PTA) $(5,6,9,15,19,25)$, the occurrence (and/or duration) of $\operatorname{LOC}(5,6,14,19,22,23)$ - measures available to the clinician early following TBI or by functional outcomes (e.g., neuropsychological test performance $(4,9,15,17$, $19,21,22,24,26)$, behavioral tests, or other functional questionnaires $(5,6,9,10,22,26)$ (Tables 3 and 4). One study focused solely on severe TBI (4), while three were concerned with mild TBI only $(6,10,16)$. Structural brain imaging was examined in relation to olfactory outcomes in a number of studies $(12-14,18$, 24, 27) (Table 4).

In total, the studies referenced at least three olfactory constructs (sensitivity/threshold, identification, discrimination), 13 olfactory "instruments" [including olfactory event related potentials (ERPs)], administered in at least three different ways (unirhinal, birhinal, retronasal) and cited olfactory outcomes classified either categorically (e.g., normal/hyposmia/anosmia), as raw or scaled scores (relative to population norms) or according to change in olfactory performance over time. Olfactory "impairment" was, for the most part, defined by reference to a defined threshold or cut-off on an olfactory test. This approach also provided the opportunity to report a rate (incidence or prevalence) of impairment. In other studies, a significant mean reduction in olfactory performance in the post-TBI group relative to appropriate controls was reported, indicating impairment in some individuals. The University of Pennsylvania Smell Identification Test (UPSIT) was the olfactory instrument most commonly used (4, $8,11,17,20-23,28)$ followed by the Sniffin' Sticks $(6,7,10,12)$ (Tables 5-8).

The interval between the TBI and olfactory testing ranged from 2 weeks $(16)$ to many years $(5,17)$, and in some cases, it was not reported. Several studies compared different techniques for assessing post-TBI olfaction, including functional brain imaging or electrophysiological techniques $(8,12,21)$. A single study employed qualitative techniques to focus on the functional consequences of post-TBI olfactory impairment (25) (Tables 5-8).

\section{MAIN FINDINGS}

Of the studies that examined olfaction following mild TBI (6, 16) [or presumptive mild TBI (10)], the findings were mixed. Among athletes reporting concussion, there were no differences on olfactory testing relative to controls although, surprisingly, longer elapsed time since the most recent concussion was associated with significantly worse olfaction (6). This finding contrasted with those from longitudinal studies based on individuals with more severe TBI in which the overall trend was toward improvement in olfactory test performance over time, although post-TBI anosmia rarely if ever reverted to normal olfaction (7,23). Among 111 individuals with mild TBI, 26\% scored in an impaired range on an olfactory threshold test at 2 weeks post-injury (16). In a study of boxers including, apparently, many currently active in the sport, of whom approximately one-third had experienced at least one "knock out," 28\% were hyposmic, and as a group their olfactory performance was significantly worse than their matched controls (10). The results suggest that mild TBI or recurrent blows to the head might have an impact on olfaction, at least in the short term.

Of the studies that examined the relationship between olfactory function and severity of TBI, the findings were also mixed although for the most part they indicated an association $(11,14$, $15,17,19,24)$. A methodologically strong study by Levin et al. (24) included controls and the sample selection minimized bias; three different means of defining TBI severity (GCS, PTA, duration of LOC) were employed; and olfactory functioning was assessed using the Olfactory Identification Test (which includes naming and recognition trials). Olfactory tests were administered between 0.2 and 84 months after the injury and in all cases after resolution of PTA. Individuals with a GCS within the 13-15 range with mass lesions were combined with data from the GCS 9-12 group. Based on this assignment of severity, both the moderate and severe groups differed from the control group on olfactory tests and the trend for a decline in olfactory naming and recognition from mild to moderate and severe groups approached significance. Similar findings held when the duration of impaired consciousness or the duration of PTA was used to classify TBI severity. In each case, the mild group did not differ significantly from controls. Using the UPSIT, Callahan and Hinkebein found an inverse association with injury severity (GCS), but the relationship only emerged with the exclusion of individuals who failed tests of effort, many of whom had mild TBI and did relatively more poorly on olfactory testing (17). Sandford et al. divided pediatric patients with TBI into severity groups according to GCS, and assessed olfaction using the San Diego Children's Odor Identification test (14). Only three children had olfactory dysfunction and as a group they had lower GCSs than those without. In another study, of 115 individuals examined at 3 months and 1 year post-TBI, the incidence of olfactory dysfunction was 22.3 and $13.5 \%$, respectively [based on the Brief Smell Identification Test (B-SIT)] and there was no relationship of olfaction with TBI severity levels as defined by GCS (9). However, anosmia was more common in the severe TBI group, and performance on the B-SIT was significantly associated with verbal fluency performance, arguably a proxy for injury severity. A similar correspondence of olfactory test results with neuropsychological 
Table 1 | Main findings.

\begin{tabular}{lll}
\hline Reference & Study design & Main purpose \\
\hline $\begin{array}{ll}\text { Parma et al. (4) } \\
\text { Cross } \\
\text { sectional }\end{array}$ & $\begin{array}{l}\text { To investigate implicit olfactory abilities in a group of anosmic } \\
\text { Individuals with TBI, matched with TBI patients with mild or } \\
\text { no olfactory problems }\end{array}$ \\
$\begin{array}{ll}\text { Neumann } \\
\text { et al. (5) }\end{array}$ & $\begin{array}{l}\text { Cross } \\
\text { Sharland- }\end{array}$ & Cross investigate if olfaction is associated with affect \\
Verville et al. & sectional & To investigate if concussion(s) are associated with \\
(6) & & reductions in olfactory performance in athletes
\end{tabular}

\section{Main findings}

Evidence for implicit olfactory processing even when explicit olfactory testing suggests anosmia

Olfactory deficits may be indicative of affect recognition impairments and reduced empathy

No difference on olfactory measures (Sniffin Sticks) between controls with no history of concussion and those with one or multiple concussions. Longer delay since concussion was associated with worse performance on identification score. The investigators speculate that concussions may have a degenerative effect on olfactory function

Welge-Lussen Longitudinal To determine long-term recovery rates of post-traumatic et al. (7) olfactory disorders and evaluate whether lateralized disorder influences recovery

\section{Gerami et al. Cross} (8) sectional

Sigurdardottir Longitudinal et al. (9)

Vent et al. (10) Cross sectional

Fortin et al. Cross (11) sectional

$\begin{array}{ll}\text { Haxel et al. } & \text { Cross } \\ \text { (12) } & \text { sectional }\end{array}$

Rombaux et al. Cross

(13) sectional
To examine the results of SPECT in anosmic subjects after closed head trauma, relative to no TBI normal controls, and look at the effect of olfactory stimulation on the SPECT results with orbitofrontal lobe the region of interest

To estimate the incidence of olfactory dysfunction across TBI severity (defined by GCS) and decision making deficits with regard to intracranial lesion-localization and laterality

Determine if boxers, as a group undergoing recurrent head trauma, demonstrate differences in olfactory performance relative to healthy controls

Compare the use of the UPSIT with the AST in TBI patients. Examine these data in relation to injury severity (GCS defined), depressive symptoms, awareness of olfactory impairment

Determine the incidence of olfactory dysfunction after head trauma using clinical, psychophysical, radiological, electrophysiological techniques. Efforts made to obtain unbiased estimates using sampling from a TBI cohort using a combination of inquiry, screening with the B-SIT, and follow up testing with the Sniffin Sticks

To evaluate olfactory function with orthonasal and retronasal testing in patients with post-TBI olfactory loss and the relationship between residual olfactory function and olfactory bulb volume
$27 \%$ of patients improved at least six points on the composite score of the Sniffin Sticks over a more than 6 years interval. Lateralized olfactory dysfunction did not correlate with improvement rate

Statistically different brain perfusion between cases and controls on all measures

Incidence of olfactory dysfunction was $22 \%$ at 3 months and $13.5 \%$ at 1 year. No association of olfactory dysfunction (as continuous variable) with TBI severity (although anosmia was). Verbal fluency (but not lowa Gambling Task) was associated with olfactory tests

Boxers as a group performed significantly worse on the olfactory threshold and odor identification components of the Sniffin Sticks. There was an association of better olfactory performance with cushioning of the gloves

The two tests were significantly correlated. Frontal lesions were associated with worse performance on olfactory tests. Mood and injury severity were not associated with olfaction. About $40 \%$ of individuals were unaware of olfactory deficits

Estimated incidence of olfactory dysfunction after TBI was $12.8 \%$. Olfactory dysfunction was related to skull based fractures and intracranial hemorrhage or hematoma

There was an association between olfactory function and olfactory bulb volume and this was stronger for retronasal olfactory testing. Olfactory bulb volumes were lower in those with paraosmia than those without 
Table 1 | Continued

\begin{tabular}{lll}
\hline Reference & Study design & Main purpose \\
\hline $\begin{array}{ll}\text { Sandford et al. } \\
(14)\end{array}$ & $\begin{array}{l}\text { Cross } \\
\text { sectional }\end{array}$ & $\begin{array}{l}\text { To evaluate olfactory function in children with blunt head } \\
\text { trauma }\end{array}$
\end{tabular}

\section{Main findings}

Children with blunt head injury may suffer post-traumatic olfactory impairment. There was an association between olfactory tests scores on the San Diego Children's Odor Identification Test and TBI severity (when stratified "mild" or "moderate and severe" by GCS)

Green et al. Cross (15) sectional

De Kruijk et al. Cross (16) sectional

Callahan and Cross Hinkebein (17) sectional

Fujii et al. (18) Longitudinal

Green and Cross Iverson (19) sectional

Yousem et al. Cross (20) sectional

Geisler et al. Cross (21) sectional

$\begin{array}{ll}\text { Callahan and } & \text { Cross } \\ \text { Hinkebein (22) } & \text { sectional }\end{array}$

Doty et al. (23) Cross sectional sub-group longitudinal
Define the primary sites of injury in patients with post-traumatic anosmia and hyposmia with MRI imaging and determine if these sites correlated with olfactory tests

Investigate the relationship between brain injury severity and brain imaging abnormalities and olfactory test scores (AST), and neuropsychological test performance. All participants were involved in some form of compensation or medical disability claim. Individuals who failed symptom validity tests were excluded from analyses

Determine the incidence of olfactory dysfunction 2 weeks after mTBI using an olfactory threshold test

To examine the performance characteristics of two forms of the University of Pennsylvania Smell Identification Test UPSIT (a 3-item version and the 40-item version) in a sample of individuals with TBI

Investigate the changes in olfactory performance following a local injection of steroids into the nasal mucosa of patients with post-TBI olfactory impairment. Mean interval since injury was 6.6 months. No controls or placebo were included To examine the relationship between exaggeration and scores on a test of olfactory discrimination in patients being assessed in connection with a claim for financial benefits

Examine the relationship between olfactory event-related potentials (OERPs) and olfactory test and neuropsychological performance in a sample of individuals with TBI related olfactory change and controls

To test the hypothesis that post-TBI anosmic patients do more poorly on measures of executive functioning and functional outcome than post-TBI patients without olfactory impairments

To examine olfactory function (and change in olfaction over time) and the influence of age, sex, TBI severity, time since $\mathrm{TBI}$ on this in patients with TBI who had presented initially with olfactory complaints. MRI brain imaging results were also examined in relation to olfactory symptoms and signs
Olfactory test scores predicted CT scan abnormalities, duration of PTA, GCS and LOC better than any of the neuropsychological scores singly or in combination

Twenty-two percent of 111 patients had hyposmia and $4 \%$ had anosmia

Fifty-six percent of the sample had impaired olfaction on the full UPSIT, $40 \%$ of them were unaware of their deficits. Missing one item of the 3-item test related to a 2:1 likelihood of being anosmic. Nearly $20 \%$ of those who scored perfectly on the 3-item test scored in the anosmic range on the 40-item UPSIT

On T\&T Olfactometry, 35 and $23 \%$ improved on recognition and detection thresholds, respectively

In patients with a TBI who failed tests of effort, there was no association between injury severity and total scores on the smell test. By contrast, in those who did pass a test of effort, there was an association between injury severity and olfactory performance

The olfactory bulbs (89\%), subfrontal lobes (61\%), and temporal lobes $(31 \%)$ showed the highest incidence of post-traumatic encephalomalacia. Left olfactory bulb and left tract volumes correlated with left and total UPSIT scores

OERPs were related to olfactory test performance

As a group, TBI patients with anosmia performed more poorly on a variety of executive function tasks and had greater disability than TBI patients without olfactory impairment

Although there may be some improvement in symptoms and signs, patients with post-TBI olfactory dysfunction rarely regain normal olfactory ability 
Table 1 | Continued

\begin{tabular}{llll}
\hline Reference & Study design & Main purpose & Main findings \\
\hline Levin et al. (24) & $\begin{array}{l}\text { Short term } \\
\text { longitudinal }\end{array}$ & $\begin{array}{l}\text { To investigate the effects of closed head injury on olfactory } \\
\text { identification and examine the relevance of TBI severity, }\end{array}$ & Olfaction worse in TBI patients than in non-TBI \\
& & location of focal damage on this & severe TBI. Hematoma or contusion in the \\
& & frontal/temporal regions was related to olfactory & recognition
\end{tabular}

$\begin{array}{lll}\begin{array}{l}\text { Drummond } \\ \text { et al. (25) }\end{array} & \begin{array}{l}\text { Cross } \\ \text { sectional }\end{array} & \begin{array}{l}\text { Describe the impact of olfactory impairment on daily } \\ \text { activities and social participation from the perspective of the } \\ \text { patient with TBI related olfactory impairment }\end{array} \\ \text { Ruff et al. (26) Longitudinal } & \begin{array}{l}\text { Observational study of a cohort of veterans with mild TBI } \\ \text { subject to headaches, residual neurological deficits, } \\ \text { post-traumatic stress disorder (PTSD). Olfaction was } \\ \text { assessed. They were treated with sleep hygiene counseling } \\ \text { and prazosin }\end{array}\end{array}$

Joung et al. Longitudinal Does frontal skull base fracture have an impact on the (27) occurrence and recovery of anosmia and/or agneusia following frontal TBI

Olfactory dysfunction has significant impact on a range of activities and social roles

Reduced clinical manifestations following mTBI correlated with PTSD severity and improvement in sleep, but not olfactory impairment

\begin{abstract}
Among 102 patients who had hemorrhage or contusion on the frontal lobes, anosmia was present in 22 (21.6\%) of whom 20 had bilateral frontal lobe injuries. Frontal skull base fracture did not otherwise increase the rate of anosmia in this sample but recovery from anosmia was greater in those without fracture
\end{abstract}

Hirsch and Cross To use an olfactory threshold test and a (suprathreshold) Wyse (28) sectional olfactory identification test to infer the localization of the olfactory pathway lesions (i.e., peripheral or central) in 13 patients with post-TBI olfactory impairment

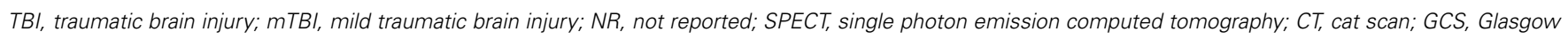
Coma Scale; PTA, post-traumatic amnesia; LOC, loss of consciousness; AST, Alberta smell test.

test performance was also evident in the studies of Green and colleagues $(15,19)$. Fortin et al. found that $69 \%$ of 49 individuals admitted to an outpatient's rehabilitation program demonstrated impaired olfaction with no difference in rates according to TBI severity (11).

Estimates of the risk of olfactory dysfunction following a TBI are likely to vary in part due to factors, such as study-specific differences in the choice of olfactory tests and the cut-offs for "impairment," different spectrums of TBI severity (and the means by which this was determined), and the interval of time since injury. Within the clinical studies reviewed in detail, the reported prevalence of olfactory dysfunction among cases with "mild" TBI was: $20 \%$ (9), 23\% (15), 26\% (16), 44\% (17); among those with "moderate" TBI: 37\% (9), 68.4\% (17); with "moderate to severe" TBI: 49\% (15), 56\% (5); and with severe TBI:33\% (9), 61\% (17).

Haxel et al. attempted to minimize bias by using a stepped approach to the detection of olfactory dysfunction in a TBI-injured group identified through hospital records (12). Using a combination of subjective report, screening with the B-SIT, and definitive testing with the Sniffin' Sticks, they estimated an overall prevalence of post-TBI olfactory dysfunction of $12.8 \%$ (12). In agreement with several other studies, they found significant rates of unawareness of olfactory dysfunction $(5,11,17,22)$ and evidence for increased risk of olfactory impairment associated with fractures to the base of skull and/or frontal hematomas (15, 20, 23, 24, 27). Hirsch and Wyse administered suprathreshold olfactory identification tests (the UPSIT and the Connecticut Home Olfactory Test) and olfactory threshold tests and defined two patterns of post-TBI dysomia (28). In one group, olfactory sensitivity was impaired but odor identification preserved. In the second group, scores were abnormal on both tests. They hypothesized that the first pattern would be consistent with peripheral pathology (e.g., olfactory nerves) while the second pattern might reflect pathology in central olfactory pathways or centers 


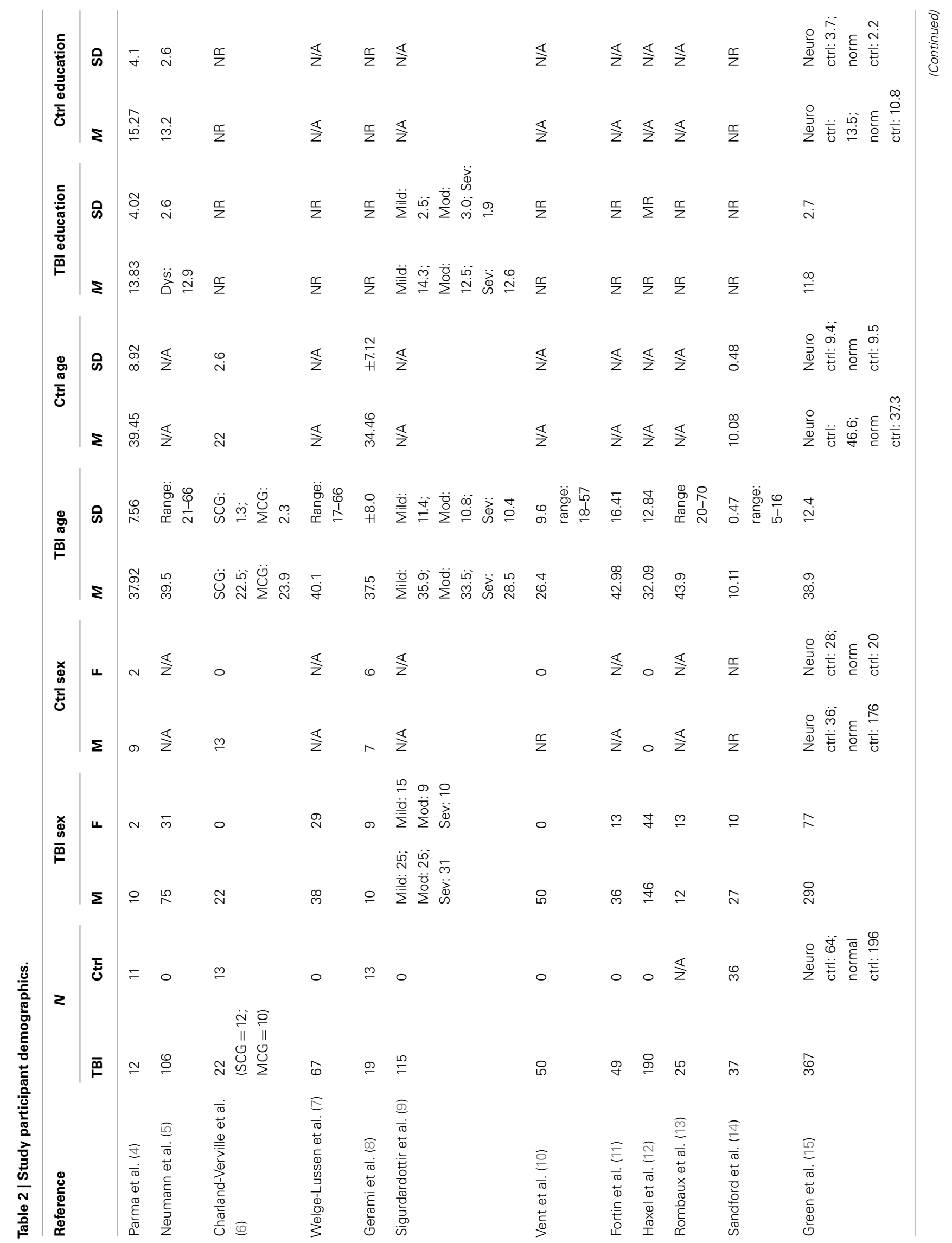




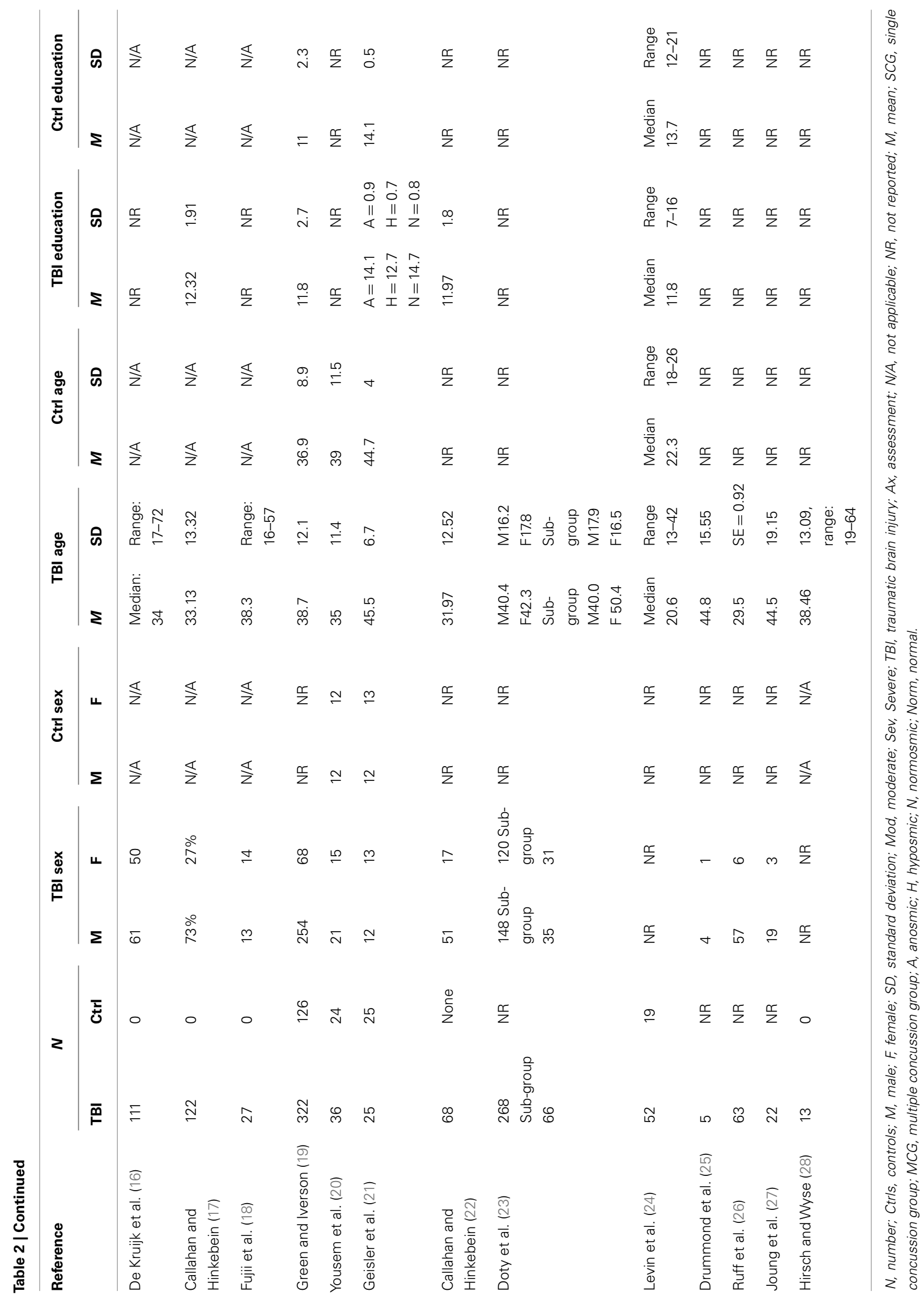


Table 3 |TBI characteristics.

\begin{tabular}{|c|c|c|c|c|c|c|c|c|}
\hline Reference & $\begin{array}{l}\text { TBI severity criteria } \\
\text { (GCS, PTA, LOC) }\end{array}$ & $\begin{array}{l}\text { Mild } \\
\text { TBI } \\
(n)\end{array}$ & $\begin{array}{l}\text { Mod } \\
\text { TBI } \\
(n)\end{array}$ & $\begin{array}{l}\text { Sev } \\
\text { TBI } \\
(n)\end{array}$ & GCS score & PTA score & LOC time & $\begin{array}{l}\text { Time } \\
\text { since } \\
\text { injury }\end{array}$ \\
\hline $\begin{array}{l}\text { Neumann } \\
\text { et al. (5) }\end{array}$ & $\begin{array}{l}\text { GCS (at the time of injury): } \leq 12 \text {; } \\
\text { PTA: } \geq 24 \mathrm{~h} ; \text { LOC: } \geq 24 \mathrm{~h}\end{array}$ & 0 & NR & NR & M: 5.38 & > 7 days: $76 \%$ & $\begin{array}{l}\text { Mean: } \\
53.57 \text { days }\end{array}$ & $\begin{array}{l}M: 11.54 \text { years, } \\
\text { range } \\
1-42 \text { years }\end{array}$ \\
\hline $\begin{array}{l}\text { Charland- } \\
\text { Verville et al. } \\
\text { (6) }\end{array}$ & $\begin{array}{l}\text { Graded from one to three } \\
\text { according to the AAN guidelines }\end{array}$ & 22 & 0 & 0 & All 13-15 & $\begin{array}{l}n=12 ; \text { no other } \\
\text { details }\end{array}$ & $\begin{array}{l}n=7 ; \text { no other } \\
\text { details }\end{array}$ & $\begin{array}{l}\text { SCG } M \text { : } \\
26.9 \text { months, } \\
\text { SD: } 21.9 \text {; MCG } \\
\text { M: } 3.9 \text { months, } \\
\text { SD: } 26.4 \text {. }\end{array}$ \\
\hline $\begin{array}{l}\text { Gerami et al. } \\
\text { (8) }\end{array}$ & NR & NR & NR & NR & NR & NR & NR & NR \\
\hline $\begin{array}{l}\text { Sigurdardottir } \\
\text { et al. (9) }\end{array}$ & GCS, PTA, and LOC classification & 40 & 34 & 41 & $\begin{array}{l}\text { Mild: } M: 14.7 \\
(0.6) \\
\text { Mod: } M: 10.8 \\
(1.3) \\
\text { Sev: M: } 5.5 \\
(1.8)\end{array}$ & $\begin{array}{l}\text { Mild: } M: 0.08 \\
\text { range: } 0-1 \\
\text { Mod: } M: 5.25 \\
\text { range: } 0-30 \\
\text { Sev: } M: 35.83 \\
\text { range: } 0-128\end{array}$ & NR & $\begin{array}{l}\text { T1: } 3 \text { months; } \\
\text { T2: } 1 \text { year }\end{array}$ \\
\hline Vent et al. (10) & $\begin{array}{l}\text { No TBI as such, rather repetitive } \\
\text { blows to the head (boxing). }\end{array}$ & N/A & $\mathrm{N} / \mathrm{A}$ & N/A & N/A & N/A & N/A & NR \\
\hline $\begin{array}{l}\text { Haxel et al. } \\
\text { (12) }\end{array}$ & GCS & 32 & 94 & 64 & NR & NR & NR & 6-32 months \\
\hline $\begin{array}{l}\text { Rombaux et al. } \\
\text { (13) }\end{array}$ & NR & NR & NR & NR & NR & NR & NR & $\begin{array}{l}\text { M: } 14.9 \text { months, } \\
\text { range } \\
\text { 3-60 months }\end{array}$ \\
\hline $\begin{array}{l}\text { Sandford et al. } \\
\text { (14) }\end{array}$ & GCS score & 31 & 3 & 3 & NR & NR & $\begin{array}{l}\text { Positive } n=15 \\
(40.5 \%) ; \\
\text { Questionable: } \\
n=7(18.9 \%)\end{array}$ & $\begin{array}{l}\text { M: } 189.45, \text { SD: } \\
9.66, \text { range: } \\
\text { 113-277 days }\end{array}$ \\
\hline $\begin{array}{l}\text { Green et al. } \\
\text { (15) }\end{array}$ & $\begin{array}{l}\text { GCS: Mild: 13-15; Mod: 9-12; } \\
\text { Sev: 3-8 }\end{array}$ & 112 & 12 & 23 & $\begin{array}{l}\text { Median } \\
\text { Scores: Mld: } \\
\text { 15; Mod: } \\
\text { 10.5; Sev: } 6\end{array}$ & $\begin{array}{l}\text { Mean (SD) } \\
\text { Scores (h): } \\
<1 \text { day: 3.0(4.5); } \\
\text { 1-10 days: } \\
\text { 88.5(55); } \\
>10 \text { days: } \\
726(650) .\end{array}$ & NR & NR \\
\hline
\end{tabular}


Table 3 | Continued

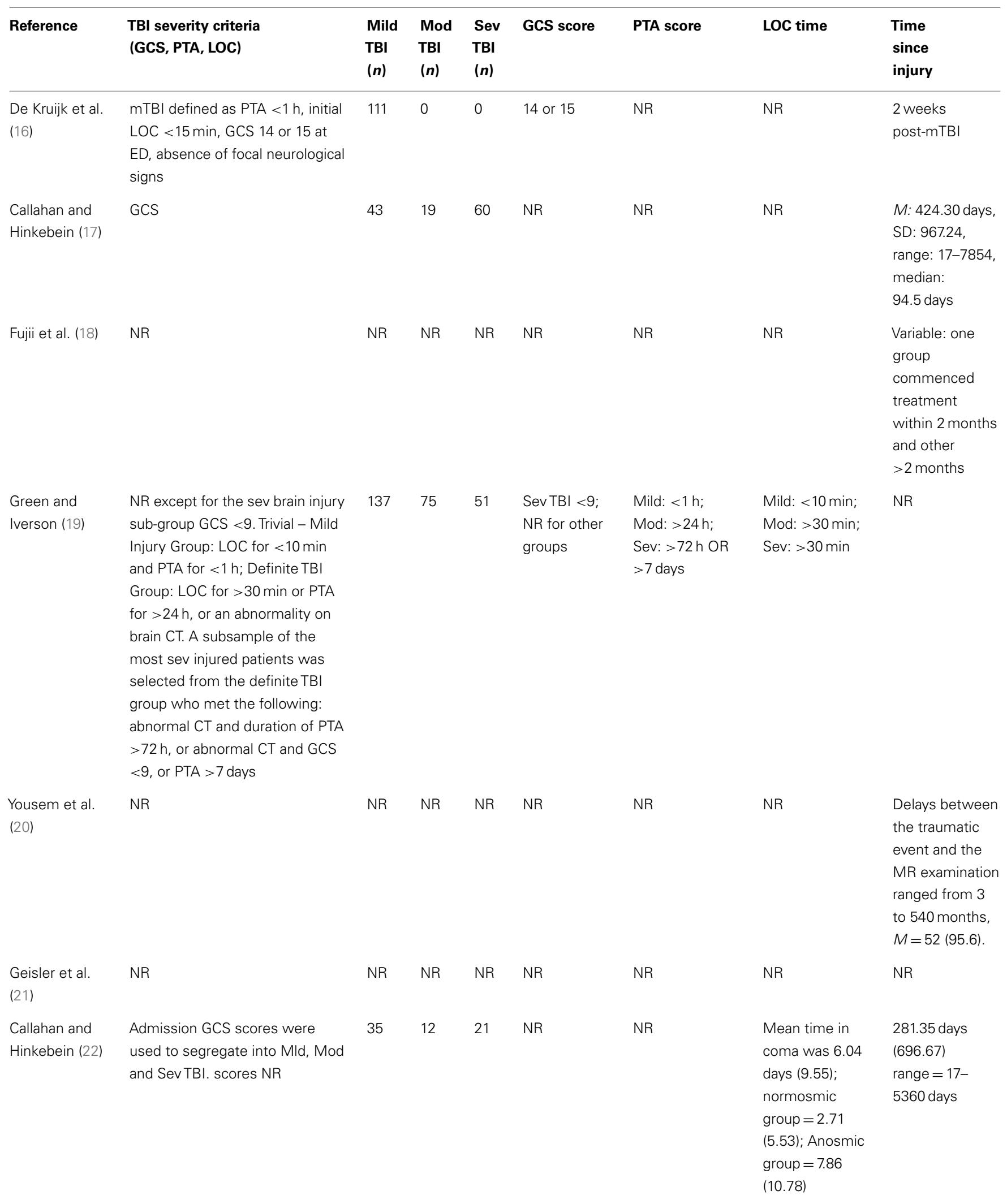


Table 3 | Continued

\begin{tabular}{|c|c|c|c|c|c|c|c|c|}
\hline Reference & $\begin{array}{l}\text { TBI severity criteria } \\
\text { (GCS, PTA, LOC) }\end{array}$ & $\begin{array}{l}\text { Mild } \\
\text { TBI } \\
(n)\end{array}$ & $\begin{array}{l}\text { Mod } \\
\text { TBI } \\
(n)\end{array}$ & $\begin{array}{l}\text { Sev } \\
\text { TBI } \\
(n)\end{array}$ & GCS score & PTA score & LOC time & $\begin{array}{l}\text { Time } \\
\text { since } \\
\text { injury }\end{array}$ \\
\hline Doty et al. (23) & $\begin{array}{l}\text { NR in main group but in } \\
\text { sub-group LOC was used }\end{array}$ & NR & NR & NR & NR & NR & $\begin{array}{l}\text { UPSIT Scores } \\
>18 \\
\text { non-anosmic } \\
\text { group, } n=18 ; \\
\text { LOC zero } n=5 ; \\
\text { LOC }<24 \mathrm{~h} \\
n=9 ; \text { LOC } \\
>24 \mathrm{~h} n=4\end{array}$ & NR \\
\hline Levin et al. (24) & GCS, PTA & 7 & 18 & 27 & $\begin{array}{l}\text { Mild 13-15 } \\
\text { Mod 9-12 } \\
\text { Sev <8 }\end{array}$ & NR & NR & $\begin{array}{l}\text { Median: Mild } \\
\text { 11.1; Mod 7; Sev } \\
3.9\end{array}$ \\
\hline $\begin{array}{l}\text { Drummond } \\
\text { et al. (25) }\end{array}$ & GCS, PTA & NR & NR & 5 & $\begin{array}{l}\text { Participant } \\
\text { 1-4 } 10.5 \text { (5.2) } \\
\text { Participant } 5 \\
\text { UK }\end{array}$ & $25.4(23.5)$ & NR & $363.6(515.7)$ \\
\hline Ruff et al. (26) & $\begin{array}{l}\text { AOC following the TBI }<24 \mathrm{~h} \text {, } \\
\mathrm{LOC}<30 \text { min, or PTA }<24 \mathrm{~h}\end{array}$ & 63 & NR & NR & NR & NR & NR & 2.5 years \\
\hline $\begin{array}{l}\text { Joung et al. } \\
(27)\end{array}$ & GCS & NR & NR & NR & 13.5 & NR & NR & 4.5 days \\
\hline $\begin{array}{l}\text { Hirsch and } \\
\text { Wyse (28) }\end{array}$ & NR & NR & NR & NR & NR & NR & NR & NR \\
\hline
\end{tabular}

N, number; Ctrls, controls; M, male; F, female; SD, standard deviation; Mod, moderate; Sev, severe; GCS, Glasgow Coma Scale; PTA, post-traumatic amnesia; LOC,

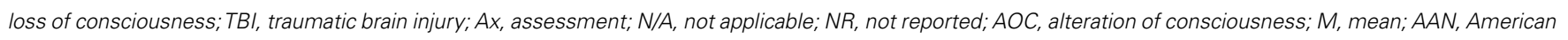
Academy of Neurology.

(28). Yousem et al. obtained high resolution magnetic resonance images of the olfactory bulbs and tracts and temporal lobes and related the findings to performance on the UPSIT, an odor memory test, and an olfactory threshold test, in cases with TBI and controls (20). The olfactory bulbs and tracts (89\%), subfrontal lobes $(61 \%)$, and temporal lobes $(31 \%)$ of 36 patients showed the highest incidence of encephalomalacia and the left olfactory bulb and tract volumes showed a significant correlation with left and total UPSIT scores (20). The close proximity of the olfactory bulbs and tracts to the frontal lobes made dual pathology commonplace.

Several studies sought associations between post-TBI olfactory dysfunction and behavioral measures or other markers of neuropsychiatric dysfunction $(5,9,22)$. In one study, individuals with post-TBI dysosmia performed more poorly on tests of affect recognition, emotional inference, and empathy (5). In another study, despite comparable GCS scores, the anosmic group displayed worse performance than the normosmic group on tests of memory and executive functioning and greater functional impairment as coded by the Disability Rating Scale (22).

Drummond, Douglas, and Oliver administered a semistructured interview to five individuals who had sustained a severe TBI and had demonstrated olfactory dysfunction. All participants reported that the olfactory impairment had limited their ability to engage in specific activities including eating and enjoyment of food, food preparation, personal safety and hygiene, work, leisure, and personal relationships (25).

\section{DISCUSSION}

The potential consequences of TBI are diverse. Injury severity varies enormously and numerous, complex pathophysiological mechanisms initiated by TBI alter the brain function acutely and beyond. Neuroanatomical and kinetic factors render the peripheral and central olfactory structures highly vulnerable to TBIrelated damage, as reflected in the high prevalence of post-injury olfactory dysfunction reported here.

The results of this review confirm that post-TBI olfactory dysfunction is common. If persistent, it represents the loss of an important sensory function with potential functional consequences as eloquently outlined in the qualitative study cited immediately above (25). Remarkably, many individuals who suffer this complication appear to be unaware of it. Finally, its presence seems to signal an increased likelihood of adverse cognitive and other neuropsychiatric and functional outcomes. The implications of these findings are worth considering at the extremes of TBI severity. 


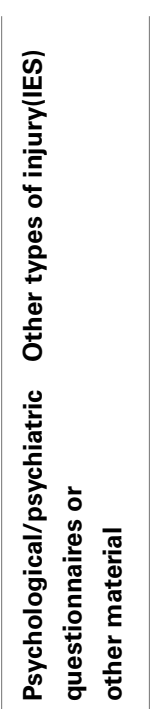

$\frac{m}{2} \quad \frac{m}{2}$

$\frac{\infty}{2} \quad \frac{m}{2}$

$\frac{\infty}{2} \quad \frac{n}{2}$

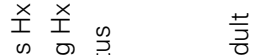
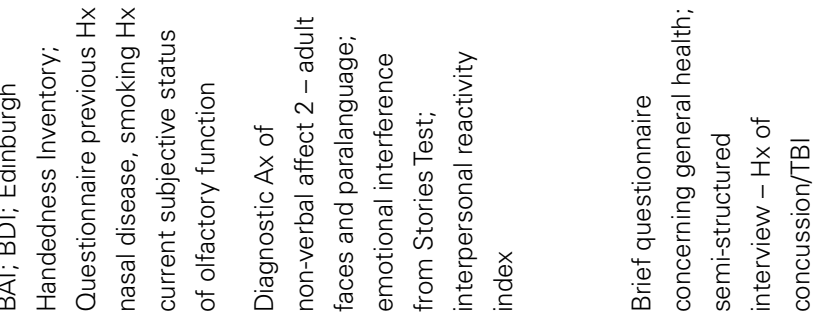

$\frac{4}{z}$

$\stackrel{\pi}{\Sigma}$

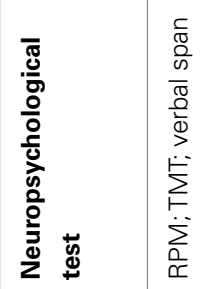

$\frac{\pi}{2}$

$\stackrel{5}{2}$

$\frac{\pi}{z} \quad \frac{\pi}{z}$

$\frac{\pi}{2}$

$\stackrel{\frac{\pi}{2}}{2}$

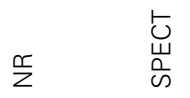
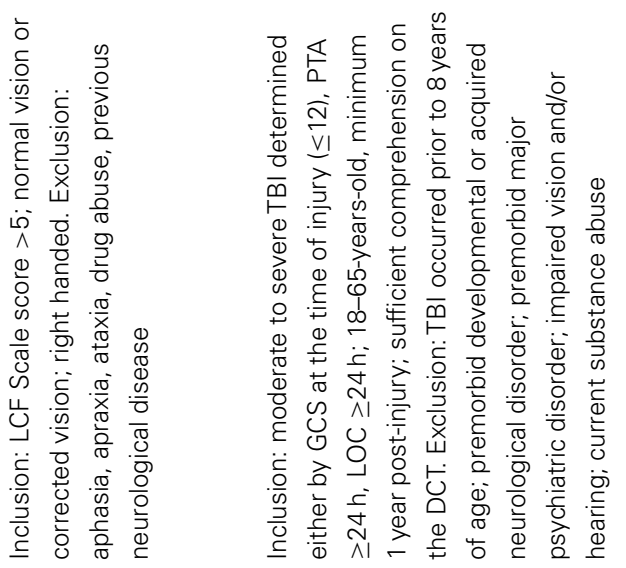

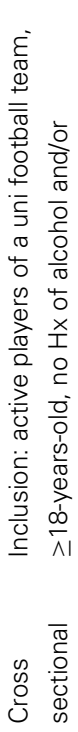
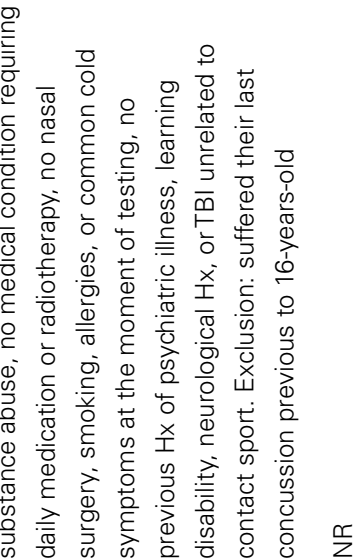

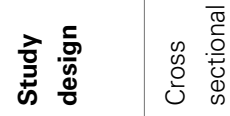
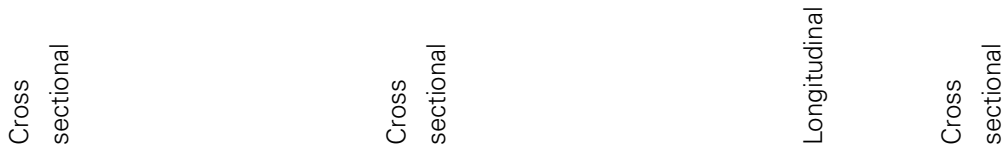

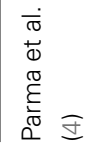

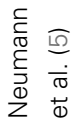

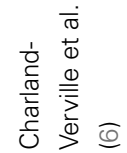

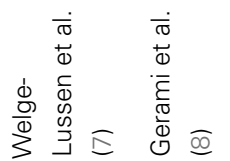




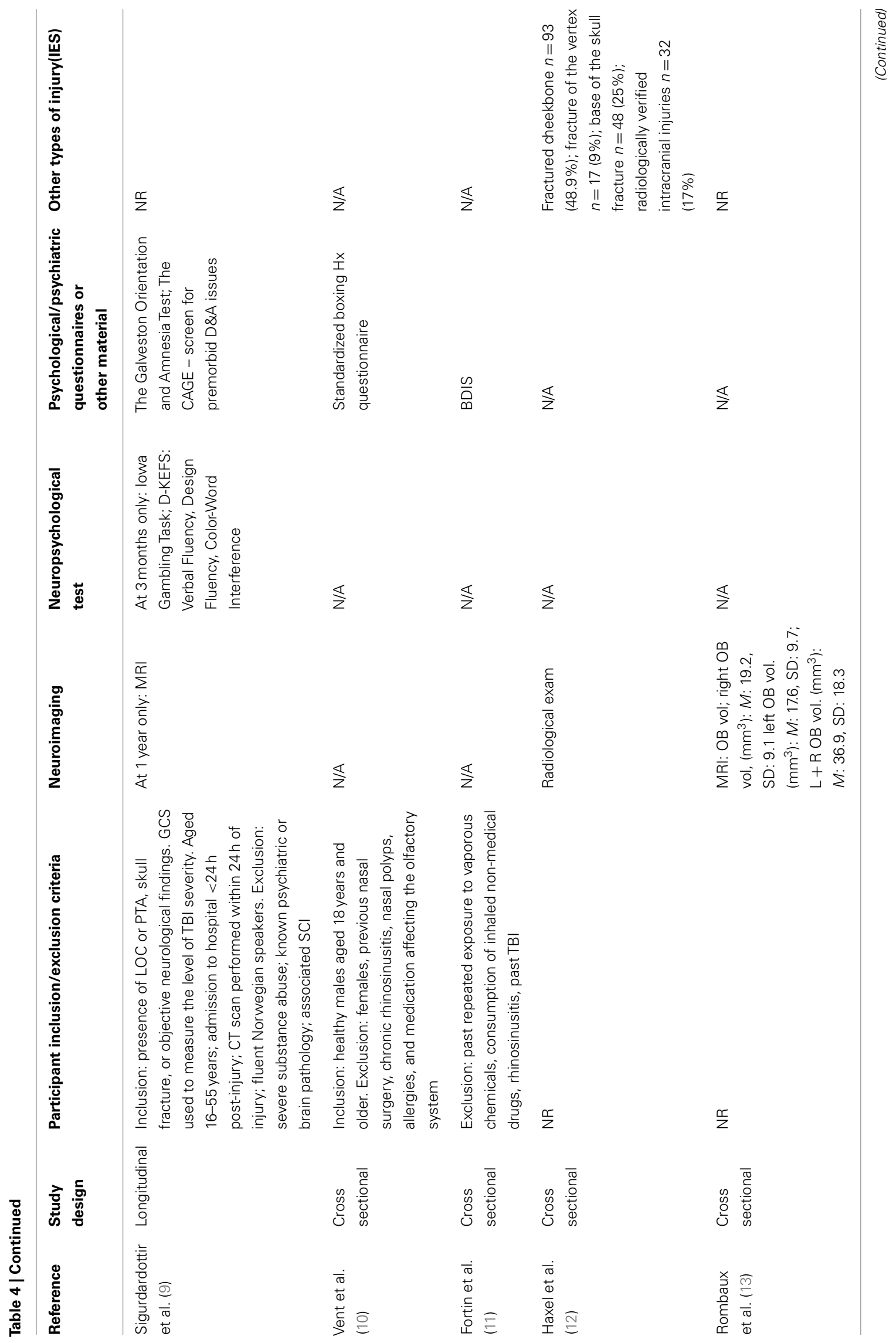




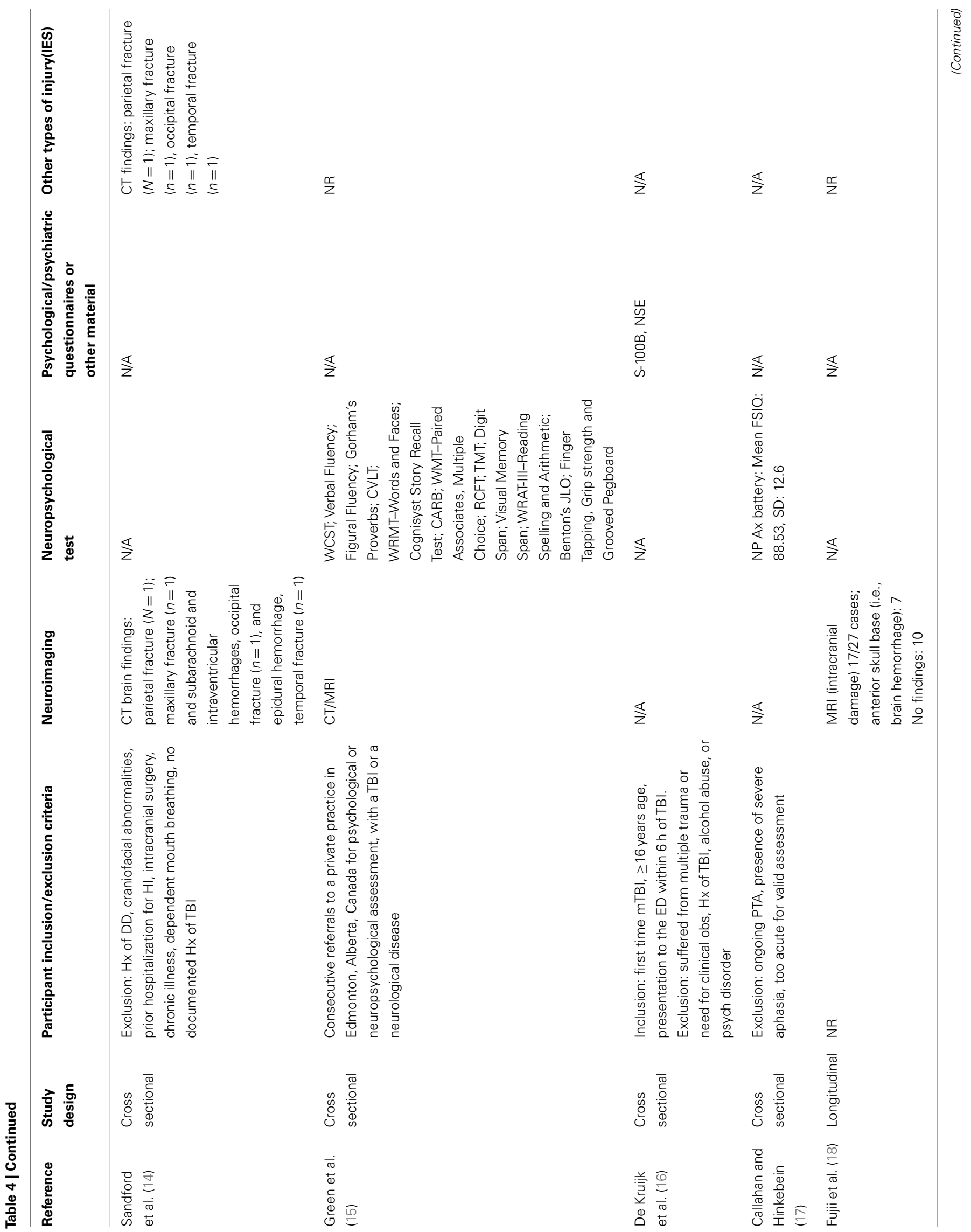




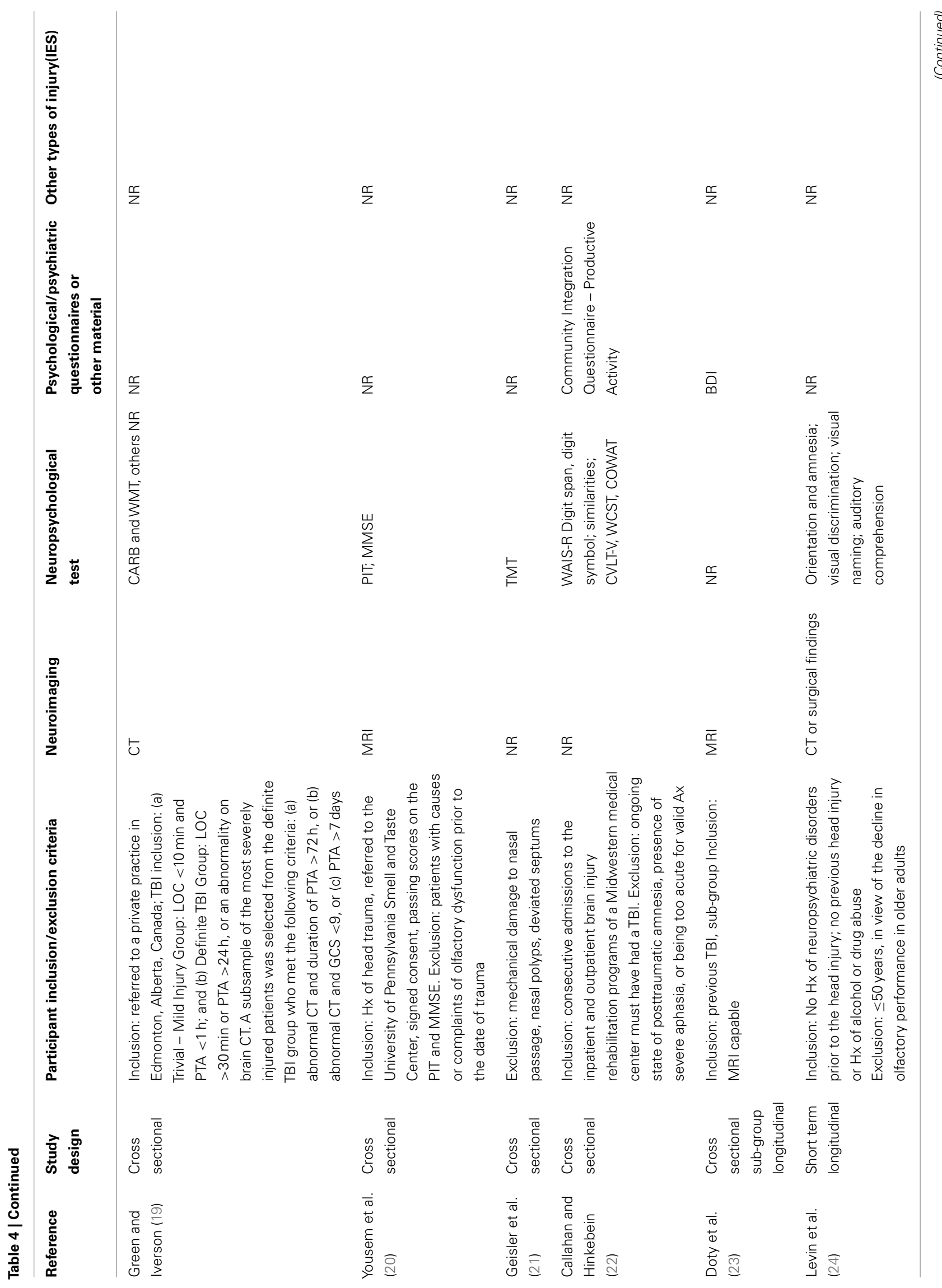




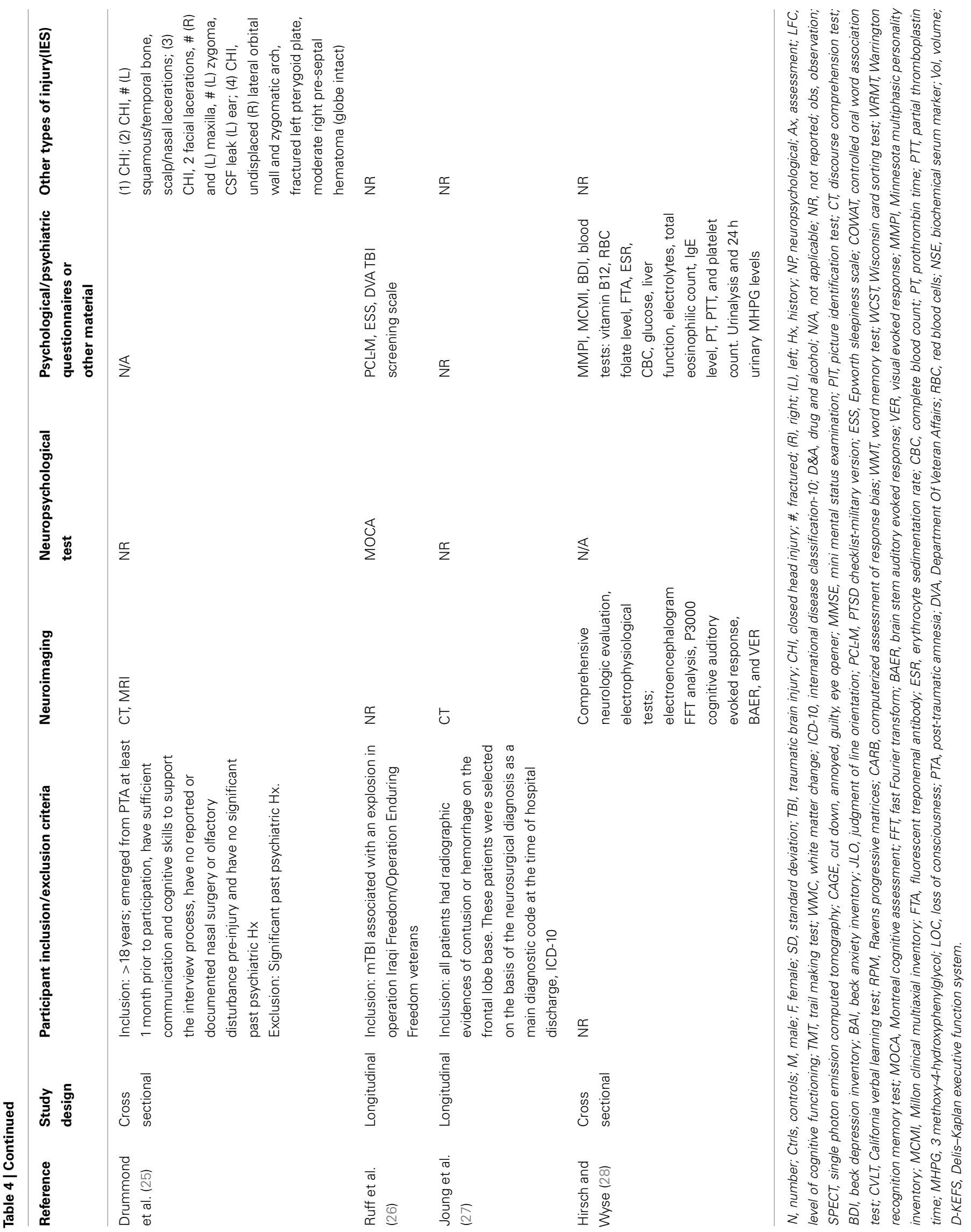




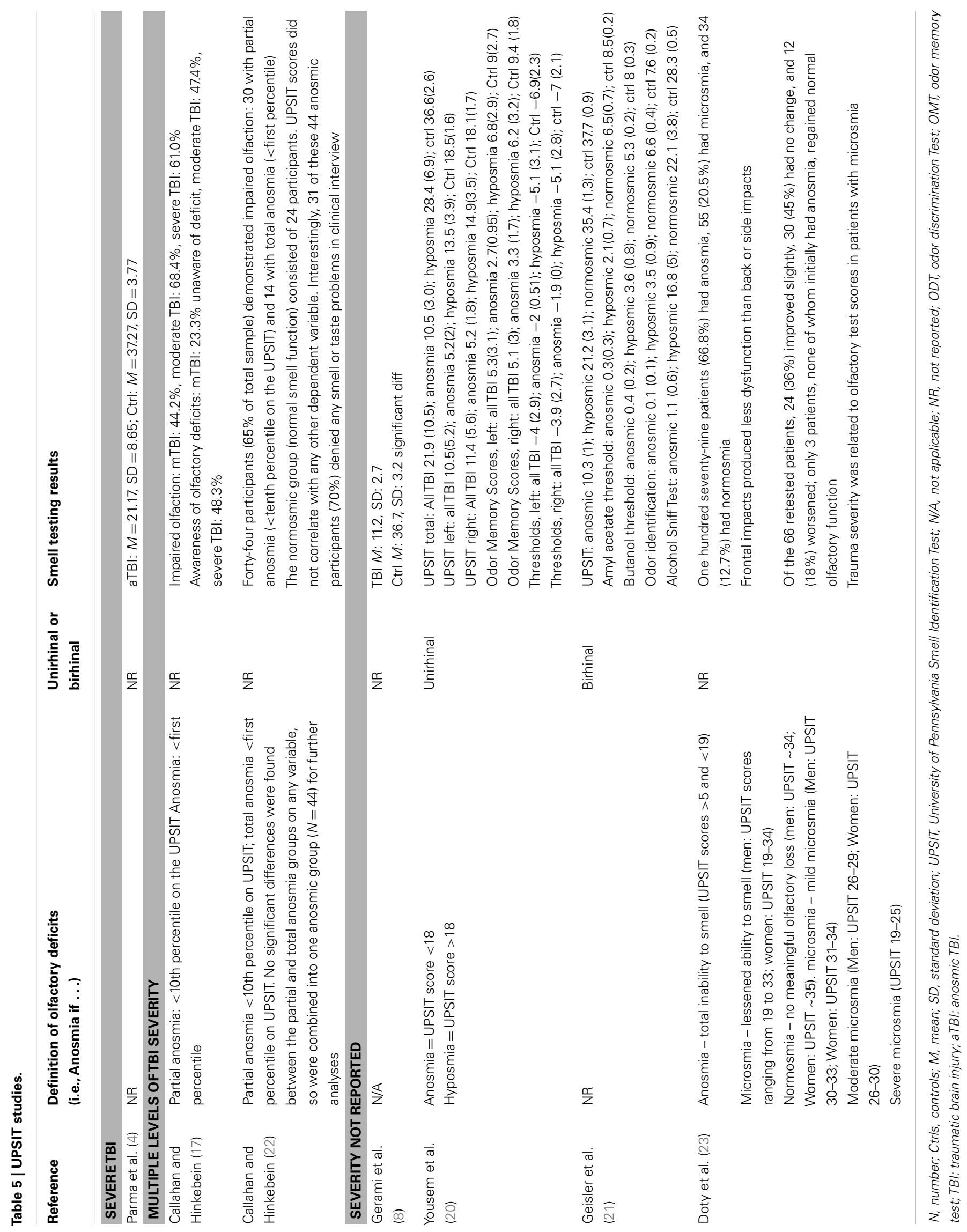




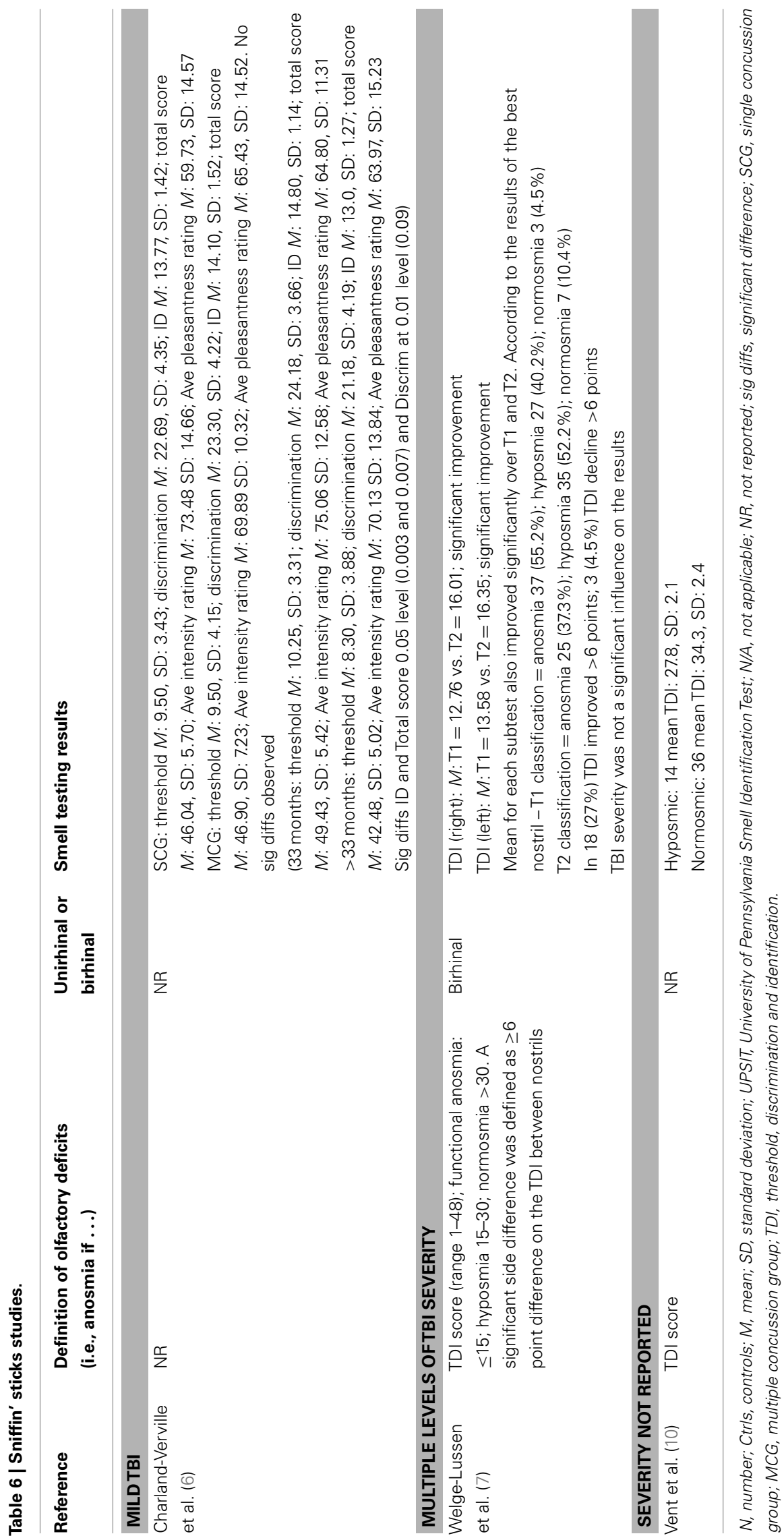




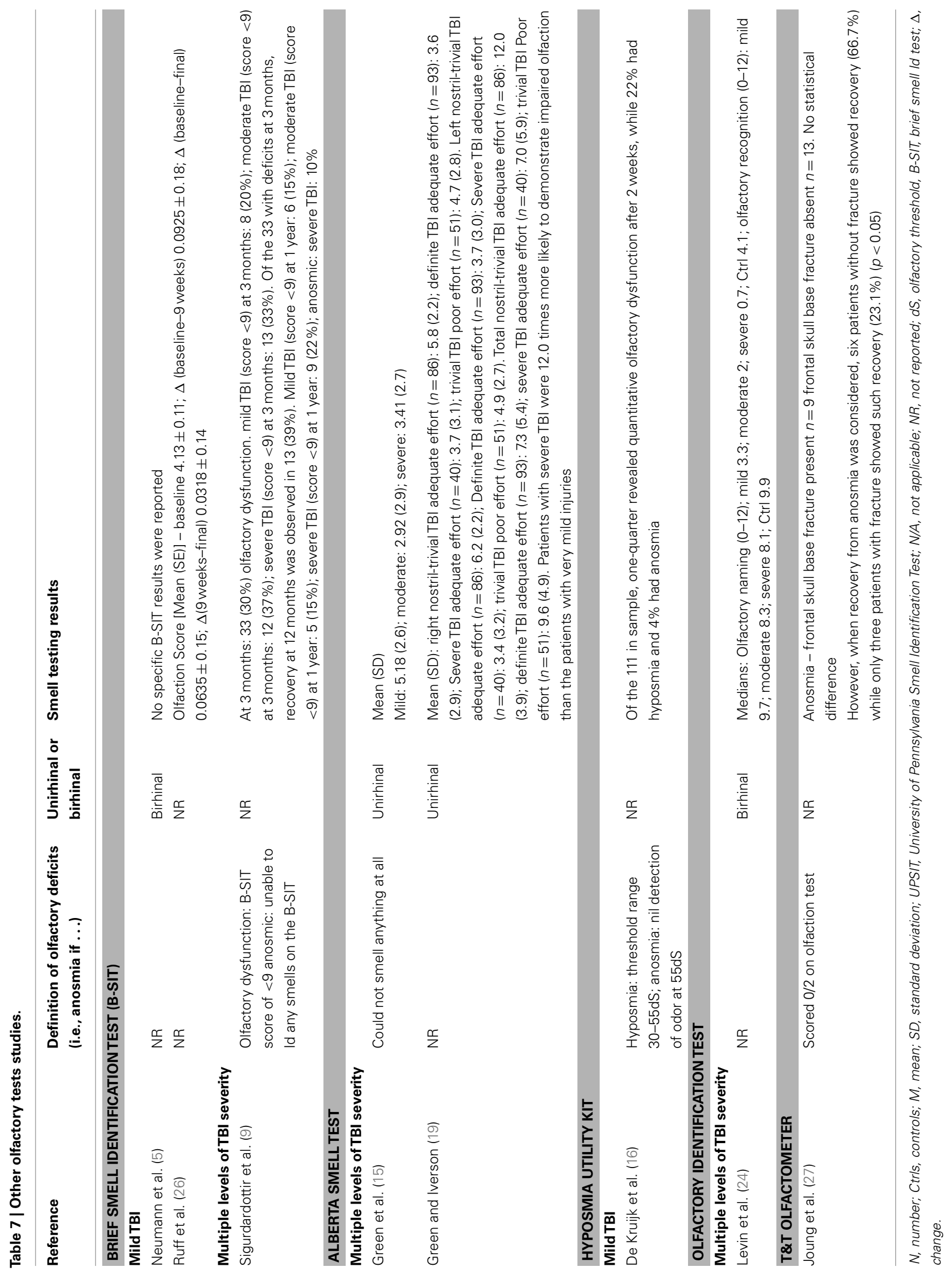




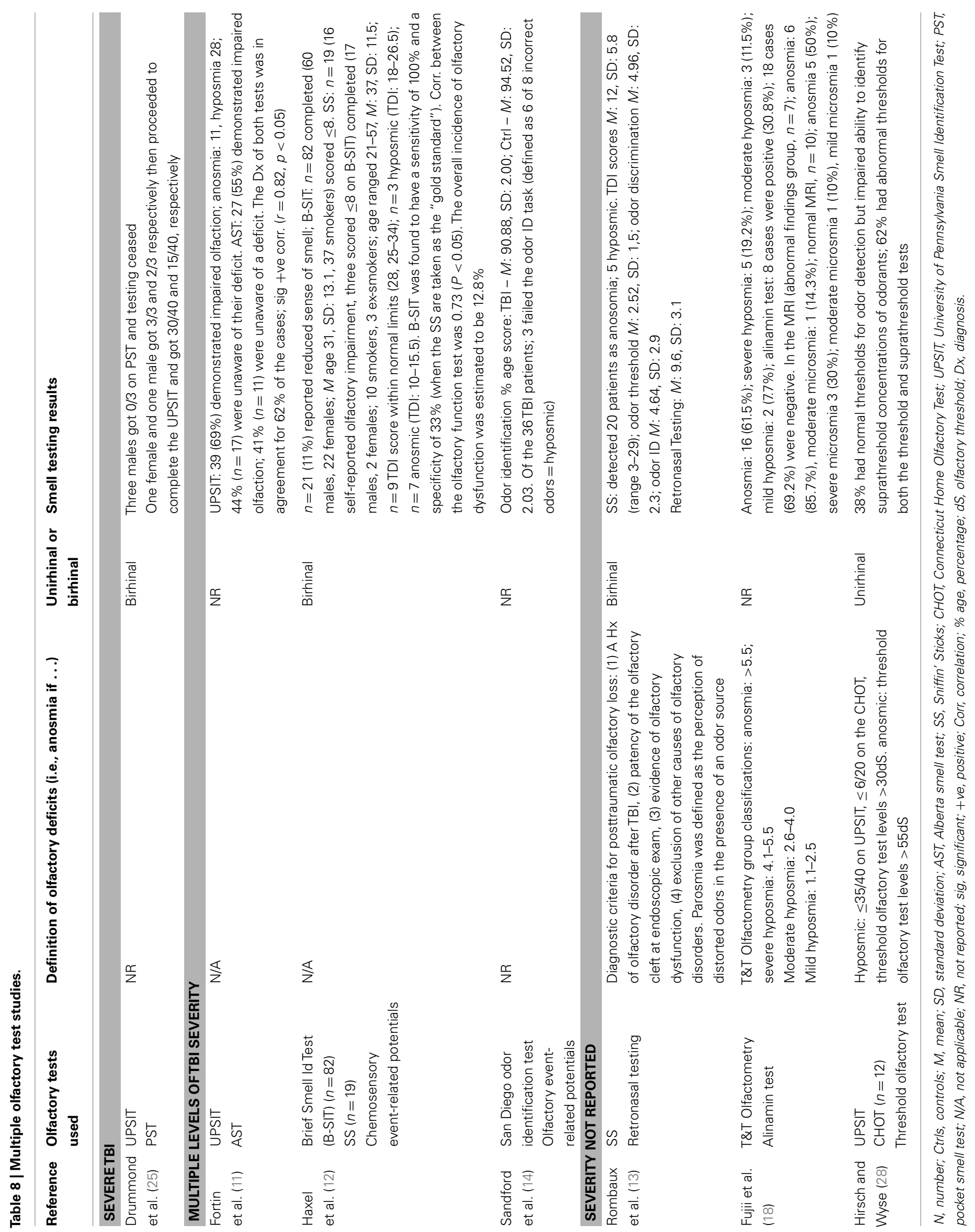


Individuals who sustain severe TBI typically undergo brain imaging and receive medical services and rehabilitative efforts over extended periods. Optimally, neuropsychiatric and neuropsychological assessments are a routine component of this care. Ideally, this comprehensive and extended engagement should explicitly identify all TBI-related complications. The cognitive and behavioral changes of severe TBI are likely to diminish the capacity to deal effectively with risky situations such as, for example, fire or a gas leak. Identification before discharge of profound anosmia, which would further impair the early detection of such dangers could be justified as a clinical imperative. Severe TBI may lead to changes in social and occupational roles including, perhaps in males particularly, an increased role with food preparation with inherent risks for individuals with anosmia.

By contrast, "mild" TBI often attracts minimal if any clinical evaluation. Nevertheless, in some cases it may be far from benign. Intracerebral contusion and/or hemorrhage, as well as persisting cognitive or behavioral changes have been reported, albeit uncommonly (24). Several of the studies included in this review suggest that the identification of dysosmia/anosmia in a patient with mild TBI could serve to flag an increased likelihood of such unexpected complications $(22,24)$. In our view, more high quality studies evaluating olfaction and its correlates following mild TBI are needed. In light of the limited scope of the existing studies in this patient group, clarification of the evolution and clinical significance of any early post-injury olfactory changes would be invaluable.

The number and diversity of olfactory instruments and techniques available present a challenge for clinicians and researchers who wish to compare results across studies. It is beyond the scope of this review to venture specific recommendations regarding the "best" choice of instruments or the design of a "minimum data set" for future studies, even if the goal of "harmonization" is a worthy one. Financial resources, time, context, and the particular research question at hand clearly bring their own imperatives and necessarily influence such choices. As a general principle, however, the use of olfactory tests with good normative data, appropriate to the culture in which the study is to be conducted, is to be strongly encouraged. Ease of between-study comparisons would be enhanced if investigators were to consistently report both rates of olfactory impairment (based on well-defined criteria) and aggregated olfactory test score data (e.g., as expressed by group specific means \pm standard deviation) as the latter measure does not necessarily easily convert to the former metric (i.e., prevalence of impairment).

As clinicians who routinely evaluate cognition, we are struck by the parallels between this activity and the conduct and interpretation of olfactory testing. The analogy holds in the context of TBI specifically. For both cognition and olfaction, the absence of symptoms cannot be relied upon to indicate intact functioning, or complaints to predict impairment on objective testing. Brevity of a screening instrument, while "convenient," usually comes at the cost of reduced sensitivity but some testing is (almost always) better than none at all. Age, gender, and many extraneous factors may affect performance and, in the absence of a previous "premorbid" assessment, the etiological significance of a single abnormal test result may be difficult to determine, although the clinical context (and pre-test probability of impairment) are clearly relevant. Patients' occupational and social responsibilities (viz. the cognitive or olfactory functioning challenges associated) might sensibly dictate who to prioritize for testing but such a strategy needs a background level of awareness as to the possibility of problems. We hope that this systematic review will make some contribution toward raising the awareness level in relation to olfactory dysfunction following TBI.

\section{REFERENCES}

1. Sumner D. Post traumatic anosmia. Brain (1964) 87:107-20. doi:10.1093/brain/ 87.1.107

2. Doty RL, Shaman P, Dann M. Development of the University of Pennsylvania Smell Identification test: a standardized microencapsulated test of olfactory function. Physiol Behav (1984) 32:489-502. doi:10.1016/0031-9384(84)90269-5

3. Kobal G, Hummel T, Sekinger B, Barz S, Roscher S, Wolf SR. 'Sniffin' Sticks': screening of olfactory performance. Rhinology (1996) 34:222-6.

4. Parma V, Straulino E, Zanatto D, Cantagallo A, Tirindelli R, Castiello U. Implicit olfactory abilities in traumatic brain injured patients. J Clin Exp Neuropsychol (2012) 34:977-88. doi:10.1080/13803395.2012.711811

5. Neumann D, Zupan B, Babbage DR, Radnovich AJ, Tomita M, Hammond F et al. Affect recognition, empathy, and dysosmia after traumatic brain injury. Arch Phys Med Rehabil (2012) 93:1414-20. doi:10.1016/j.apmr.2012.03.009

6. Charland-Verville V, Lassonde M, Frasnelli J. Olfaction in athletes with concussion. Am J Rhinol Allergy (2012) 26:222-6. doi:10.2500/ajra.2012.26.3769

7. Welge-Lussen A, Hilgenfeld A, Meusel T, Hummel T. Long-term follow-up of posttraumatic olfactory disorders. Rhinology (2012) 50:67-72. doi:10.4193/ Rhino 11.141

8. Gerami H, Nemati S, Abbaspour F, Banan R. Brain single photon emission computed tomography in anosmic subjects after closed head trauma. Acta Med Iran (2011) 49:13-7.

9. Sigurdardottir S, Jerstad T, Andelic N, Roe C, Schanke AK. Olfactory dysfunction, gambling task performance and intracranial lesions after traumatic brain injury. Neuropsychology (2010) 24:504-13. doi:10.1037/a0018934

10. Vent J, Koenig J, Hellmich M, Huettenbrink KB, Damm M. Impact of recurrent head trauma on olfactory function in boxers: a matched pairs analysis. Brain Res (2010) 1320:1-6. doi:10.1016/j.brainres.2010.01.007

11. Fortin A, Lefebvre MB, Ptito M. Traumatic brain injury and olfactory deficits: the tale of two smell tests! Brain Inj (2010) 24:27-33. doi:10.3109/ 02699050903446815

12. Haxel BR, Grant L, Mackay-Sim A. Olfactory dysfunction after head injury. J Head Trauma Rehabil (2008) 23:407-13. doi:10.1097/01.HTR.0000341437. 59627.ec

13. Rombaux P, Mouraux A, Bertrand B, Nicolas G, Duprez T, Hummel T. Retronasal and orthonasal olfactory function in relation to olfactory bulb volume in patients with posttraumatic loss of smell. Laryngoscope (2006) 116:901-5. doi:10.1097/01.MLG.0000195291.36641.1E

14. Sandford AA, Davidson TM, Herrera N, Gilbert P, Magit AE, Haug K et al. Olfactory dysfunction: a sequela of pediatric blunt head trauma. Int J Pediatr Otorhinolaryngol (2006) 70:1015-25. doi:10.1016/j.ijporl.2005.10.013

15. Green P, Rohling ML, Iverson GL, Gervais RO. Relationships between olfactory discrimination and head injury severity. Brain Inj (2003) 17:479-96. doi:10.1080/0269905031000070242

16. de Kruijk JR, Leffers P, Menheere PP, Meerhoff S, Rutten J, Twijnstra A. Olfactory function after mild traumatic brain injury. Brain Inj (2003) 17:73-8. doi:10.1080/0269905021000010221

17. Callahan CD, Hinkebein JH. Assessment of anosmia after traumatic brain injury: performance characteristics of the University of Pennsylvania Smell Identification test. J Head Trauma Rehabil (2002) 17:251-6. doi:10.1097/00001199200206000-00006

18. Fujii M, Fukazawa K, Takayasu S, Sakagami M. Olfactory dysfunction in patients with head trauma. Auris Nasus Larynx (2002) 29:35-40. doi:10.1016/S03858146(01)00118-3

19. Green P, Iverson GL. Effects of injury severity and cognitive exaggeration on olfactory deficits in head injury compensation claims. NeuroRehabilitation (2001) 16:237-43. 
20. Yousem DM, Geckle RJ, Bilker WB, Kroger H, Doty RL. Posttraumatic smell loss: relationship of psychophysical tests and volumes of the olfactory bulbs and tracts and the temporal lobes. Acad Radiol (1999) 6:264-72. doi:10.1016/S10766332(99)80449-8

21. Geisler MW, Schlotfeldt CR, Middleton CB, Dulay MF, Murphy C. Traumatic brain injury assessed with olfactory event-related brain potentials. J Clin Neurophysiol (1999) 16:77-86. doi:10.1097/00004691-199901000-00008

22. Callahan CD, Hinkebein J. Neuropsychological significance of anosmia following traumatic brain injury. J Head Trauma Rehabil (1999) 14:581-7. doi:10.1097/00001199-199912000-00006

23. Doty RL, Yousem DM, Pham LT, Kreshak AA, Geckle R, Lee WW. Olfactory dysfunction in patients with head trauma. Arch Neurol (1997) 54:1131-40. doi:10.1001/archneur.1997.00550210061014

24. Levin HS, High WM, Eisenberg HM. Impairment of olfactory recognition after closed head injury. Brain (1985) 108:579-91. doi:10.1093/brain/108.3.579

25. Drummond M, Douglas J, Olver J. 'If I haven't got any smell. I'm out of work': consequences of olfactory impairment following traumatic brain injury. Brain Inj (2013) 27:332-45. doi:10.3109/02699052.2012.750743

26. Ruff RL, Riechers RG, Wang XF, Piero T, Ruff SS. For veterans with mild traumatic brain injury, improved posttraumatic stress disorder severity and sleep correlated with symptomatic improvement. J Rehabil Res Dev (2012) 49:1305-20. doi:10.1682/JRRD.2011.12.0251
27. Joung YI, Yi HJ, Lee SK, Im TH, Cho SH, Ko Y. Posttraumatic anosmia and ageusia: Incidence and recovery with relevance to the hemorrhage and fracture on the frontal base. J Korean Neurosurg Soc (2007) 42:1-5.

28. Hirsch AR, Wyse JP. Posttraumatic dysosmia: central vs. peripheral. J Neurol Orthop Med Surg (1993) 14:152-5.

Conflict of Interest Statement: The authors declare that the research was conducted in the absence of any commercial or financial relationships that could be construed as a potential conflict of interest.

Received: 15 November 2013; accepted: 09 January 2014; published online: 22 January 2014

Citation: Schofield PW, Moore TM and Gardner A (2014) Traumatic brain injury and olfaction: a systematic review. Front. Neurol. 5:5. doi: 10.3389/fneur.2014.00005

This article was submitted to Neurotrauma, a section of the journal Frontiers in Neurology.

Copyright (C) 2014 Schofield, Moore and Gardner. This is an open-access article distributed under the terms of the Creative Commons Attribution License (CC BY). The use, distribution or reproduction in other forums is permitted, provided the original author(s) orlicensor are credited and that the original publication in this journal is cited, in accordance with accepted academic practice. No use, distribution or reproduction is permitted which does not comply with these terms. 